\title{
ENSINO DE CIÊNCIAS: uma proposta de escolarização do conceito de morte por meio da abordagem do ciclo de vida
}

\section{SCIENCE EDUCATION: a proposal for schooling the concept of death through the life cycle approach}

\author{
Aline Andréia Nicolli ${ }^{1}$ \\ Eduardo Fleury Mortimer ${ }^{2}$ \\ Itamar Miranda da Silva ${ }^{3}$
}

\begin{abstract}
RESUMO
Neste artigo, apresentamos reflexões de um estudo desenvolvido para propor o perfil conceitual de morte e identificar aspectos da abordagem pedagógica do ciclo de vida, no Ensino de Ciências. Discutimos, mais especificamente, aspectos sobre a seguinte questão: quais as possibilidades da escolarização do conceito de morte por meio da abordagem pedagógica do ciclo de vida, no Ensino de Ciências? Os sujeitos envolvidos eram estudantes de duas turmas de sétima série, do ensino fundamental, que frequentavam aulas de ciências, em uma escola pública estadual localizada em Rio Branco, Acre, Brasil. A análise dos dados coletados permitiu perceber que a abordagem pedagógica da unidade ciclo de vida alterou expressivamente os modos de falar e as formas de pensar dos estudantes sobre o ciclo de vida e a morte.
\end{abstract}

Palavras-chave: Ensino de Ciências. Ciclo de vida.Morte.

\begin{abstract}
This article presents reflections of a study designed to propose the conceptual profile of death and identify aspects of the pedagogical approach of the cycle of life, in Science Teaching. We discuss, in particular, aspects on the following question: What are the possibilities of transforming the concept of death into a school concept, through the pedagogical approach of the cycle of life, in science teaching? The subjects involved were students from two classes of the seventh grade, of elementary education, attending science classes in a public school located in Rio Branco, Acre, Brazil. The analysis of the collected data allowed to perceive that the pedagogical approach of the cycle of life unit dramatically changed the way students talk and think about the cycle of life and the death.
\end{abstract}

Keywords: Science teaching. Cycle of life. Death.

\footnotetext{
${ }^{1}$ Centro de Educação, Letras e Artes - CELA - UFAC

${ }^{2}$ Faculdade de Educação- UFMG

${ }^{3}$ Centro de Educação, Letras e Artes - CELA - UFAC

AMAZÔNIA - Revista de Educação em Ciências e Matemáticas V.8 - no 16 - jan. 2012 / jun. 2012, p.133-145.
} 


\section{INTRODUÇÃO}

Desde criança, o que aprendemos nas aulas de ciências é que o homem é um ser vivo e, por isso, tem um ciclo de vida. No entanto, o ciclo de vida geralmente ensinado não considera os seguintes aspectos: (a) as possibilidades dos seres vivos não desenvolverem um ciclo de vida completo; (b) a percepção da vulnerabilidade do corpo, ou seja, do inevitável ponto final do ciclo de vida e da vida: a morte e (c) o fato do conceito de morte ser central na existência das pessoas, pela sua oposição ao conceito de vida.

Diante disso, as experiências profissionais por nós vivenciadas, como professores formadores, fizeram-nos (e ainda fazem-nos) refletir sobre as abordagens pedagógicas desenvolvidas no Ensino de Ciências e sobre como elas podem contemplar a discussão de alguns significados polêmicos, como é o conceito de morte, considerando os modos de falar e as formas de pensar dos estudantes.

Para Bakhtin (1981, 1986), o gênero de falas e a linguagem social são duas formas de estratificação da linguagem que asseguram a sua heterogeneidade. Uma linguagem social é "[...] um discurso peculiar a um estrato específico da sociedade (linguagem profissional, linguagem de gerações, etc.) dentro de um dado sistema social e num dado tempo" (HOLQUIST, 1981, p.430). Todas as linguagens sociais são

[...] pontos de vista específicos no mundo, formas para conceituar o mundo em palavras, visões de mundo específicas, cada uma caracterizada por seus próprios objetos, significados e valores (...), como tal elas se encontram umas com as outras e coexistem na consciência das pessoas reais (BAKHTIN, 1981, p. 291-2).

Na visão bakhtiniana, um falante sempre produz um enunciado usando uma linguagem social específica, que dá forma ao que ele pode dizer. Por outro lado,

[...] um gênero de discurso não é uma forma de linguagem, mas uma forma típica de enunciado; como tal, o gênero também inclui certas formas típicas de expressão que lhes são inerentes (...), gêneros correspondem a situações típicas da comunicação verbal, a temas típicos e, consequentemente, também a contatos particulares entre os significados das palavras e a realidade concreta, sob certas circunstâncias típicas (BAKHTIN, 1986, p. 87).

Assim, enquanto uma linguagem social está relacionada com um ponto de vista específico, determinado pela posição profissional ou geracional, o gênero de discurso está relacionado ao lugar social e institucional em que ele é produzido.

Partindo do exposto, podemos inferir que, ao responder o pré e o pós-teste, os sujeitos lançam mão de uma linguagem social típica - neste caso, estudantes de Ciências - e também, de certa forma, produzem enunciados específicos da sua condição escolar tanto para caracterizar o ciclo de vida como para conceituar morte. Por isso, destacamos que em termos de abordagem pedagógica, a pesquisa relatada neste artigo foi desenvolvida considerando as seguintes hipóteses de trabalho: 
(a) O Ensino de Ciências, quando do desenvolvimento da abordagem pedagógica, necessita reconhecer a Condição Humana, enquanto possibilidade de que o enunciado externado por cada sujeito possa expressar a sua individualidade, ou seja, suas experiências vividas, expectativas, curiosidades, dúvidas, receios e/ou apreensões.

(b) A importância de planejar a abordagem de conceitos científicos, no Ensino de Ciências, privilegiando atividades que façam emergir as falas dos sujeitos. Reconhecendo que estes se formam e se desenvolvem em interação constante e contínua com os enunciados do outro. Promover o Encontro com o Outro exige o planejamento de atividades que possibilitam a interação entre os sujeitos no espaço da sala de aula.

(c) É necessário que a ação pedagógica, no Ensino de Ciências, construa um discurso que viabilize aquilo que denominamos Respeito à Diversidade, por meio do respeito e da abordagem ${ }^{4}$ das múltiplas condições culturais, históricas e sociais que permeiam a sala de aula. Ou seja, viabilizar o Respeito à Diversidade, para promover a construção, a reconstrução e a tomada de consciência das zonas que constituem o Perfil Conceitual de um determinado conceito e, nesse caso especial, do conceito de morte.

Isto posto, em relação à abordagem pedagógica, buscamos responder a seguinte questão:(a) Quais os limites, as possibilidades e as implicações do planejamento e da abordagem pedagógica desenvolvida quando da consideração da temática Ciclo de Vida, em sala de aula, para a construção, reconstrução e a tomada de consciência, pelos estudantes, de um Perfil Conceitual de Morte?

\section{RELATANDO ASPECTOS DA ATIVIDADE REALIZADA EM SALA DE AULA}

Ao mencionarmos os procedimentos metodológicos que foram utilizados para o desenvolvimento deste estudo, faz-se necessário destacar que a pesquisa,relatada no presente artigo, caracterizava-se por ser basicamente qualitativa, pois apresentou como objetivo identificar a interferência das zonas do perfil do conceito de morte para a abordagem pedagógica do ciclo de vida, no Ensino de Ciências, no Ensino Fundamental.

O que pretendíamos era perceber os sujeitos envolvidos no estudo, como parte de um todo, em seu contexto natural, habitual, a universidade e/ ou a escola, sem perder de vista a natureza subjetiva do comportamento humano. Por isso, uma ênfase mais acentuada na pesquisa qualitativa, a nosso ver, se mostrou pertinente para esse trabalho visto que possibilitou a consideração de aspectos singulares sobre como as concepções e as abordagens pedagógicas são vivenciadas por cada sujeito. Notamos então que

a pesquisa qualitativa responde a questões muito particulares [.... ela trabalha com o universo de significados, motivos, crenças, aspirações, valores e atitudes, o que corresponde a um espaço mais profundo das relações, dos processos e dos fenômenos que não podem ser reduzidos à operacionalizações de variáveis (MINAYO, 1998, p.22).

Em termos de abordagem metodológica,a intenção era a de realizar um estudo centrado na ideia de Perfil Conceitual, que está pautada no pressuposto de que os sujeitos

\footnotetext{
${ }^{4}$ Vinculamos a expressão respeitar com a expressão abordar, porque visualizamos as duas questões como sendo necessárias para as reflexões que pretendemos realizar ao longo do estudo. Uma vez que o respeito, por si só, pode não, necessariamente, resultar no trabalho pedagógico para e com a diversidade.
} 
podem apresentar, em contextos diferenciados, maneiras diferentes de pensar e falar "as coisas" que integram seu mundo (MORTIMER, 1996, 2001). Reconhecer, em sala de aula, a existência de diferentes formas de pensar e modos de falar se faz imprescindível, ao ato de ensinar e de aprender.

A escolha dos sujeitos, por sua vez, considerou os seguintes critérios:

Aplicação de questionários com situações problema envolvendo a temática morte com duas turmas de $7^{\mathrm{a}}$ série do Ensino Fundamental. Esses questionários foram aplicados antes e depois da abordagem pedagógica da unidade Ciclo de Vida, para permitir o estudo da evolução de seus Perfis Conceituais.

Foi investigada uma escola onde o professor era Licenciado em Ciências Biológicas e demonstrou interesse em realizar uma intervenção pedagógica, em duas sétimas séries ${ }^{5}$, sobre a unidade Ciclo de Vida.

Inicialmente, aplicamos um questionário (pré-teste) para coletar os dados que permitiram identificar duas concepções para o ciclo de vida e três zonas para o perfil conceitual de morte ${ }^{6}$. Em termos de ciclo de vida, identificamos a concepção clássica e a concepção alternativa. Na primeira, agrupamos todas as respostas que conceituavam ciclo de vida, constituído, obrigatoriamente, pelo nascer, crescer, se reproduzir, envelhecer e morrer. $\mathrm{Na}$ segunda categoria,foram alocadas respostas que consideravam a possibilidade de a morte se efetivar antes da completude do ciclo, ou seja, antes do envelhecimento. Em termos de perfil conceitual de morte, identificamos ${ }^{7}$ as zonas naturalista, religiosa e relacional.

Identificadas as zonas do perfil conceitual de morte e as concepções de ciclo de vida, realizamos o planejamento da abordagem pedagógica da unidade ciclo de vida. Para tanto, permitimo-nos chamar a atenção para o fato de que fizemos uma opção por definir ciclo de vida como característica de todo ser vivo, composto obrigatoriamente pelo nascer e morrer, uma vez que acreditamos que a complexidade do ciclo de vida não apresenta variação apenas de espécie para espécie, mas também de indivíduo para indivíduo, dentro de uma mesma espécie ${ }^{8}$.

Assim sendo, esclarecemos que a abordagem nas duas turmas de $7^{\mathrm{a}}$ série do ensino fundamental, de uma escola pública estadual, localizada em Rio Branco, Acre, contemplava, em um primeiro momento, as atividades comumente propostas pela professora por ocasião do desenvolvimento de um trabalho sobre a unidade ciclo de vida. Assim, desenvolvemos aulas expositivas dialogadas, por meio das quais os estudantes entraram em contato com a caracterização do ciclo de vida completo, ou seja, nascer, crescer, se reproduzir, envelhecer e morrer.

Num segundo momento, propusemos a realização de uma atividade somente aos estudantes da $7^{\text {a }}$ série A. Nesse caso, o planejamento objetivou promover a discussão sobre

\footnotetext{
${ }^{5}$ Escolhidas de acordo com a organização curricular de Ciências, que contempla [ou deveria contemplar] a temática Ciclo de Vida e, por consequência, a morte.

${ }^{6}$ Para a construção do Modelo de Perfil Conceitual de Morte, usamos como referencial a Teoria de Perfil Conceitual, elaborada por Mortimer $(1996,2001)$ e os Modelos de Perfil Conceitual de Vida, elaborados Coutinho (2005) e Silva (2006).

${ }^{7} \mathrm{~A}$ identificação das zonas ocorreu por meio do desenvolvimento de um estudo mais amplo, em que se estabeleceu um jogo dialógico entre os elementos teóricos e os dados empíricos coletados junto aos estudantes de ensino fundamental e acadêmicos dos cursos de graduação em Ciências Biológicas, Ciências Sociais, Pedagogia e Medicina, de uma universida depública federal.

${ }^{8} \mathrm{Tal}$ opção se deu para que fosse possível considerar a abordagem da unidade de acordo com o que está posto nas propostas curriculares oficiais brasileiras e que refletem a abordagem pedagógica [embora sujeita a análises e críticas] desenvolvida em sala de aula.
} 
"outras possibilidades de constituição do ciclo de vida" e sobre "o nascer e o morrer", etapas que constituem, necessariamente, o ciclo de vida de todos os seres vivos.

Para o desenvolvimento da atividade, a turma foi organizada em 05 grupos e cada grupo recebeu uma folha de papel madeira, pincéis atômicos, colas, tesouras e revistas para recorte. Na sequência, a professora explicou à turma que a atividade exigia a construção de um painel com figuras retiradas das revistas e relatou aos estudantes a seguinte situação: "Na aula anterior, estudamos o ciclo de vida. Falávamos que ele é composto pelo nascer, crescer, se reproduzir, envelhecer e morrer. Hoje gostaríamos que vocês discutissem, com os colegas do grupo, sobre outras possibilidades de constituição do ciclo de vida". Continuou ratificando a orientação inicial de que, após a discussão das ideias, cada grupo deveria representar as possibilidades pensadas, por meio da organização de um painel com recortes de revista. A turma prontamente iniciou a atividade e, em poucos minutos, os diferentes grupos discutiam outras possibilidades de constituição do ciclo de vida e as representavam utilizando as figuras.

Buscamos, com essa atividade, possibilitar a escolarização do conceito de morte, por meio do desenvolvimento de uma abordagem pedagógica do ciclo de vida, que considerou a tríade da condição humana, do encontro com o outro e do respeito à diversidade.

Pensamos ser a consideração das três orientações acima elencadas necessárias para a promoção de discussões sobre as distintas configurações que cada um desses conceitos científicos pode assumir ao longo da vida de cada sujeito. Ou seja, tivemos a intenção de, durante a atividade, chamar a atenção dos estudantes, e agora dos leitores, para quanto se faz necessário que os conceitos abordados, no Ensino de Ciências, sejam pensados e contemplados com base na premissa de que podem comportar uma diversidade de manifestações e que, por isso, podem fazer emergir formas diferenciadas de compreensão.

Por esse motivo, a atividade desenvolvida reconheceu, num primeiro momento, a opinião singular de cada estudante, sua individualidade ou, ainda, aquilo chamado de condição humana, contemplando as diferentes ideias que podem emergir no momento da abordagem de um dado conceito.

Da mesma forma, buscamos não perder de vista a possibilidade da discussão, da reflexão conjunta, do reconhecimento da existência de vários pontos de vista, como uma abordagem pedagógica planejada com o intuito de promover o encontro com o outro.

Acreditamos que por meio da dinâmica do ouvir e ser ouvido os estudantes puderam externar suas conceituações, entrar em contato com as conceituações dos colegas e perceber as limitações conceituais que possuem, e as possibilidades, em caso de necessidade, de ampliar ou reorganizar seus conceitos. Ou seja, ao ouvir as conceituações do outro - seja do colega, seja do professor - o estudante pode tomar consciência da necessidade de reorganizar, ampliar ou mesmo abandonar uma conceituação que até então defendia.

Notamos então que devido à possibilidade de participar de situações de ensino que promovem o pensar e/ou repensar suas concepções, por meio do confronto/encontro de ideias,os estudantes abarcam, via de regra, as novas ideias apresentadas, quer pelo discurso do professor, quer pelo discurso dos colegas.

E é nesse processo de relação, entrelaçamento e complementação que a promoção do encontro com o outro se constitui, segundo Bakhtin (2003), como encontro dialógico de duas culturas, em que ocorre o enriquecimento mútuo, a aprendizagem, a construção de novos conceitos científicos e/ou a ampliação de conceitos já existentes. Nesse caso, consideramos a cultura científica escolar, do qual os professores são os representantes, e a cultura cotidiana, representada tanto pelos professores como pelos estudantes. 
Nessa perspectiva, aos professores é atribuída a responsabilidade de considerar que,

[...] ao falar, sempre [deve] levar em conta o fundo aperceptível da percepção do discurso pelo destinatário: até que ponto ele está a par da situação, dispõe de conhecimentos especiais de um dado campo cultural da comunicação; levar em conta as suas concepções e convicções, os seus preconceitos (do meu ponto de vista), as suas simpatias e antipatias - tudo isso irá determinar a ativa compreensão responsiva do enunciado por ele (BAKHTIN, 2003, p.302).

Aos estudantes compete, no entanto, a percepção de que

[...] aprender a falar significa aprender a construir enunciados (porque falamos por enunciados e não por orações isoladas e, evidentemente, não por palavras isoladas). [...] Nós aprendemos a moldar o nosso discurso [...] quando ouvimos o discurso alheio (BAKHTIN, 2003, p.283).

Embora sendo detentores de papéis específicos, professores e estudantes participam conjuntamente, em sala de aula, de um processo dialógico em que, por meio do discurso, são estabelecidas constantes relações entre o enunciado principal e outros enunciados.

Ressaltamos o fato de que a abordagem pedagógica desenvolvida, sobre ciclo de vida e da morte, exigiu, daquele que a desenvolveu em sala de aula, a veiculação de um discurso que privilegiasse o respeito à diversidade, sendo coerente e condizente com a linguagem científica, sem, no entanto, perder de vista as especificidades da linguagem cotidiana. Tivemos, assim, uma possibilidade de fazer chegar aos estudantes a compreensão de que o ciclo de vida e a morte, em questão, podem ser os de cada um e/ou os de todos os sujeitos que estão participando do processo de ensino e de aprendizagem.

Por fim, aplicamos o questionário (pós-teste) em ambas as turmas, com a finalidade de comparar os dados obtidos e as possíveis alterações nos modos de falar e nas formas de pensar utilizadas pelos estudantes para conceituar ciclo de vida e morte, antes e depois da abordagem pedagógica.

\section{APRESENTANDO ALGUNS RESULTADOS}

Inicialmente, esclarecemos que serão apresentados, neste texto, apenas os painéis confeccionados pelos grupos 01 e 03.Para tanto, destacamos que o painel, apresentado pelo grupo 01 (Fig. 01), demonstra, por meio das figuras, um ciclo de vida composto pelo nascer, crescer e morrer. Temos aqui a apresentação de uma "outra possibilidade de ciclo de vida" que remete à reflexão acerca da efetivação da morte antes do cumprimento das fases de reprodução e envelhecimento.

No segundo painel, o grupo 03 (Fig. 1), por sua vez, apresentou a representação de uma "outra possibilidade de ciclo de vida", constituído pelo nascer, crescer, se reproduzir e morrer. Nesse caso, o grupo alertou para a possibilidade de a morte ocorrer na vida de um indivíduo antes do seu envelhecimento. 

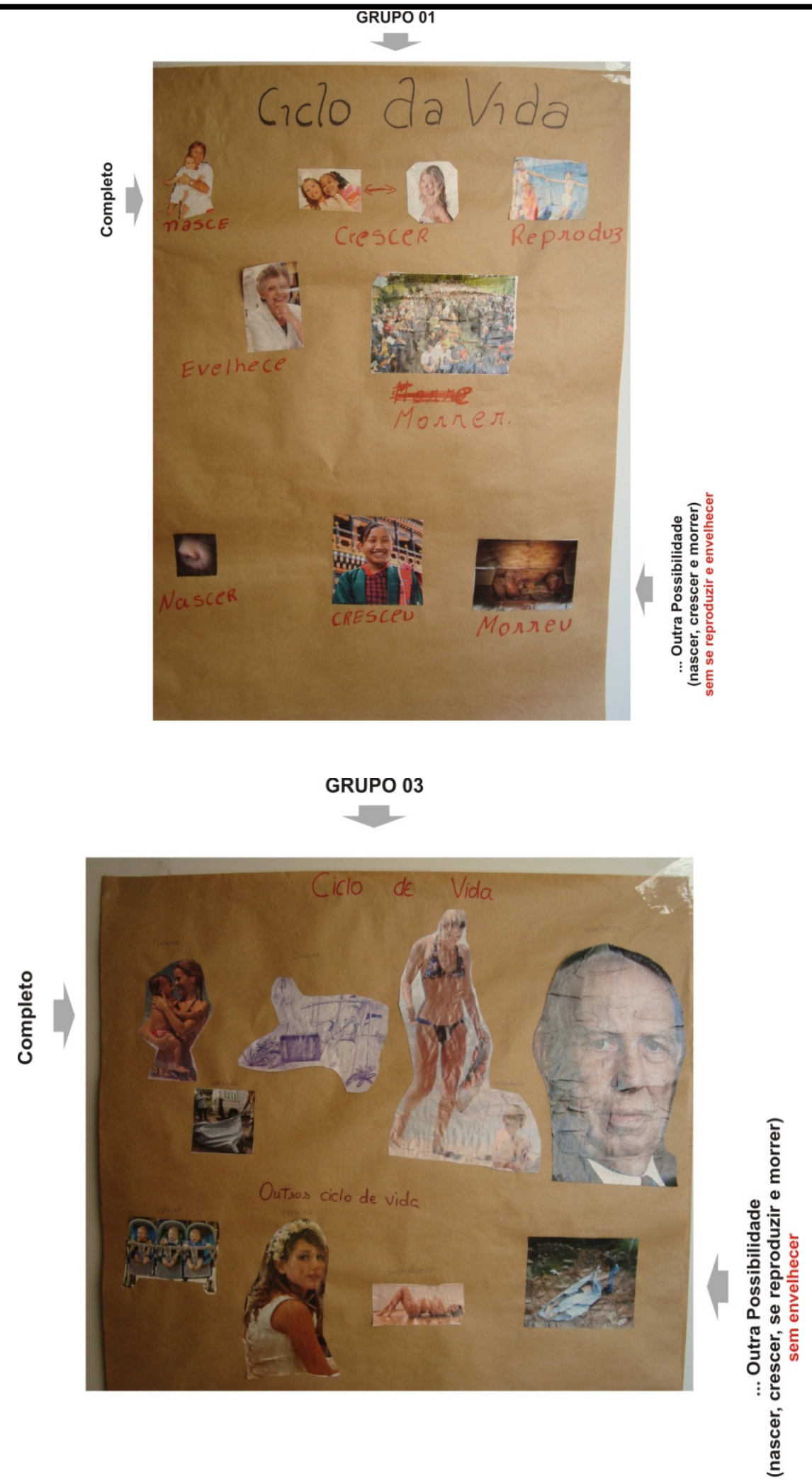

Figura 01: Painel GRUPO 01 e do GRUPO 03: outra possibilidade de ciclo de vida

Uma análise, mesmo que breve, permite perceber, especialmente nos painéis dos grupos 01 e 03 , que o ciclo de vida representado vai ao encontro daquele que defendemos constituir a melhor abordagem da temática, posto que o nascer e o morrer são de fato as fases garantidas a todos os seres vivos. Acreditamos que esse dado pode estar vinculado à 
abordagem pedagógica do ciclo de vida desenvolvida na turma, já que os estudantes puderam refletir sobre alternativas várias de constituição do ciclo de vida e sobre a possibilidade de a morte se manifestar em um sujeito que não viveu o "ciclo completo".

Após essa breve exposição acerca da atividade que compôs a abordagem pedagógica do ciclo de vida, desenvolvida exclusivamente na $7^{\text {a }}$ série A,ressaltamos os dados a seguir. Eles possibilitarão o estabelecimento de comparações acerca das concepções de ciclo de vida e de morte, externadas pelos pesquisados, das duas sétimas séries do ensino fundamental, considerando o momento do pré e do pós-teste.

A análise conjunta dos gráficos 01 e 02 permite inferir que, por ocasião do pós-teste, realizado após a abordagem pedagógica do ciclo de vida, ocorreu na $7^{\mathrm{a}}$ série $\mathrm{A}$ o aumento na incidência da categoria 'alternativa'. Ou seja, 29,1\% dos estudantes, após realizar a atividade de construção do painel apresentando "outra possibilidade de constituição do ciclo de vida", passaram a utilizar uma concepção alternativa para caracterizá-lo. Esse não foi, entretanto, o cenário encontrado entre os estudantes da $7^{\mathrm{a}}$ série $\mathrm{B}$, posto que a categoria 'clássica' apresentou aumento de percentual, do pré ao pós-teste, e a categoria alternativa se manteve inalterada.

Gráfico 01: Concepções de ciclo de vida, do pré-teste ao pós-teste, $7^{\text {ạ }}$ Série $\mathrm{A}$

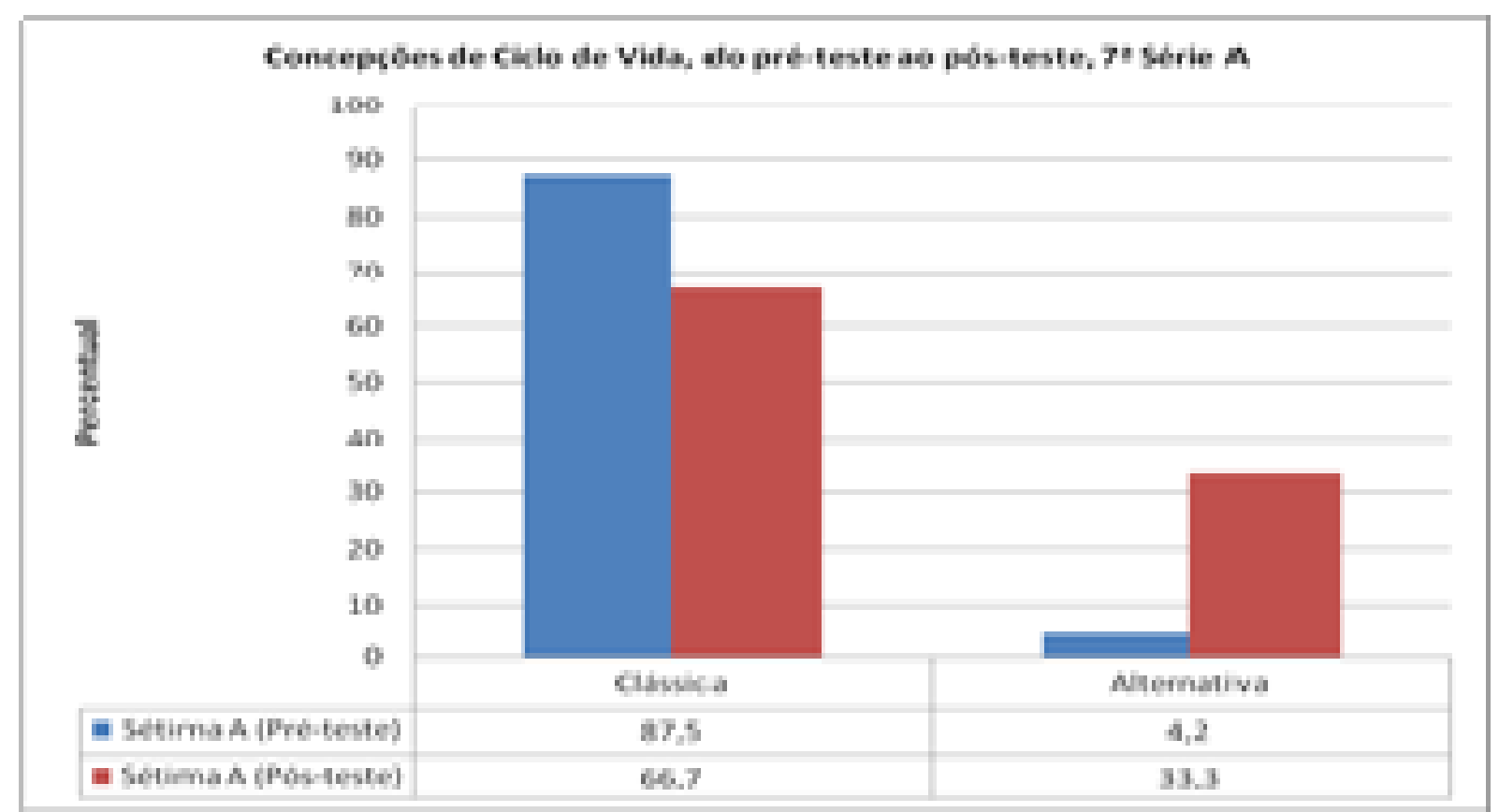


Gráfico 02: Concepções de ciclo de vida, do pré-teste ao pós-teste, $7^{\text {ạ }}$ Série B

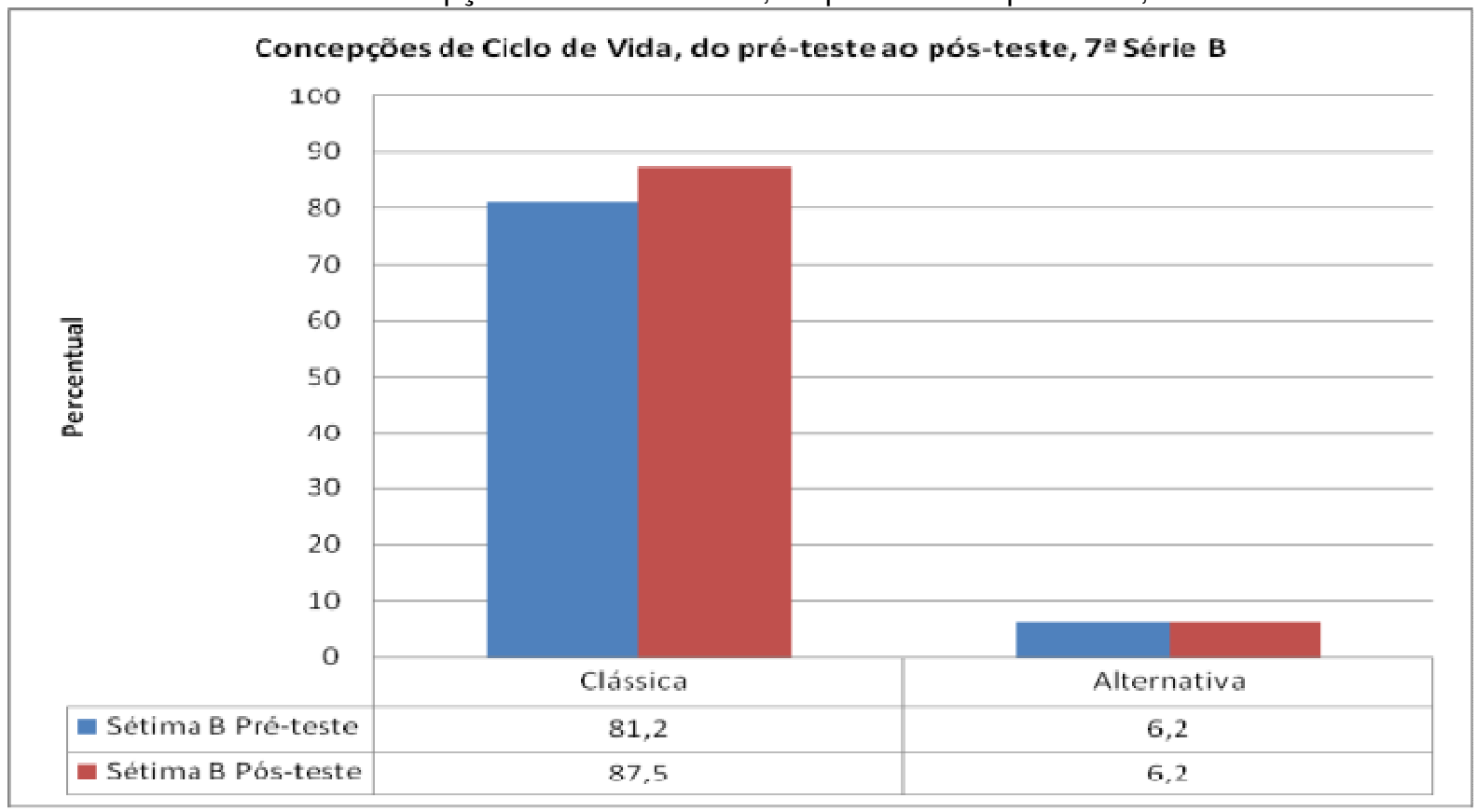

Nos gráficos 03 e 04, os dados possibilitam comparar a evolução das zonas do perfil conceitual de morte, do pré-teste ao pós-teste, nas $7^{\mathrm{a}}$ séries $\mathrm{A}$ e $\mathrm{B}$. A análise dos dados aponta que, por ocasião do pós-teste ${ }^{9}$, ocorreu na $7^{\mathrm{a}}$ série $\mathrm{A}$ um aumento na incidência da zona 'naturalista' e uma queda na zona 'religiosa'.

Os dados nos permitem perceber também que, na $7^{\text {a }}$ série $\mathrm{B}$, a zona naturalista apresentou leve aumento, enquanto as zonas religiosa e relacional apresentaram leve queda. Os dados precisam ser considerados especialmente porque indicam baixa oscilação nos resultados e porque, nessa turma, a abordagem pedagógica permitiu aos estudantes o contato com o discurso científico sobre o ciclo de vida, mas não a realização da atividade em grupo, ou seja, eles não vivenciaram a possibilidade de refletir sobre "outras possibilidades de constituição do ciclo de vida".

\footnotetext{
${ }^{9}$ Realizado após a abordagem pedagógica da unidade ciclo de vida. Na $7^{\text {a }}$ série $\mathrm{B}$, a abordagem foi a comumente desenvolvida pela professora, pautada no livro didático e em aula expositiva dialogada. Na $7^{\mathrm{a}}$ série $\mathrm{A}$, no entanto, a abordagem problematizou outras possibilidades de constituição do ciclo de vida, ou seja, promoveu a reflexão sobre o fato de que a morte pode se apresentar nas diferentes fases da vida, e não necessariamente após o envelhecimento.
} 
Gráfico 03: Evolução das zonas do perfil conceitual de morte, do pré-teste ao pós-teste, 7ª̣ Série A

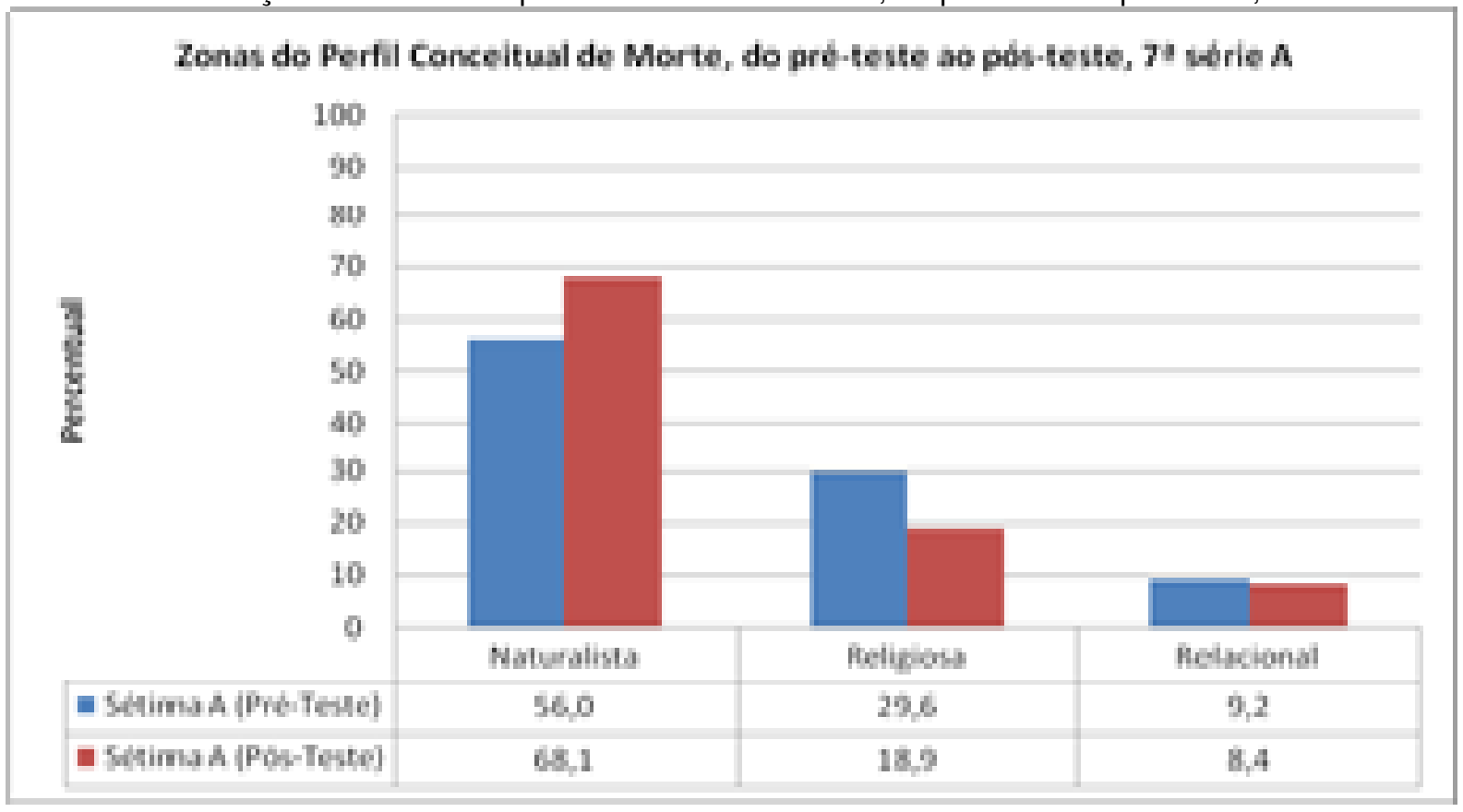

Gráfico 04: Evolução das zonas do perfil conceitual de morte,do pré-teste ao pós-teste, 7ª Série B

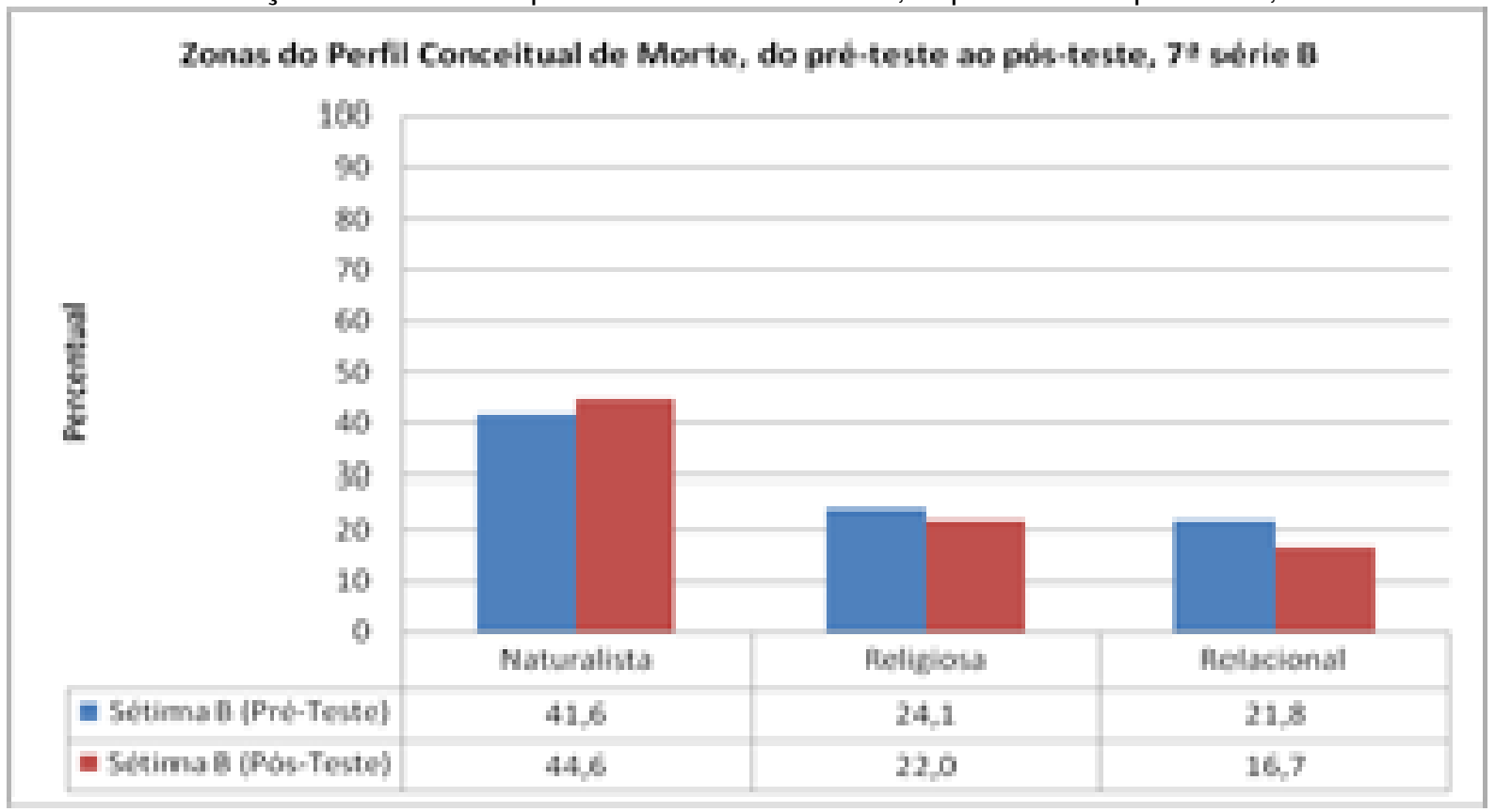

Importa destacar que os dados apresentados nos gráficos acima permitem dizer que, por ocasião da abordagem pedagógica, os estudantes tiveram acesso ao discurso científico sobre o ciclo de vida e sobre a morte, o que pode ter favorecido o aparecimento, no pós-teste, de modos de falar específicos de sala de aula e, por consequência, um maior número de sujeitos utilizando, em suas respostas, argumentos naturalistas/biológicos para conceituar a morte. Esses argumentos são os que mais se aproximam do discurso da ciência. 
Os dados coletados em sala de aula permitem perceber, também, que a abordagem pedagógica desenvolvida, neste caso específico, sobre ciclo de vida na $7^{\text {a }}$ série A promoveu mudanças mais expressivas nas formas de pensar e nos modos de falar desses estudantes sobre o ciclo de vida e a morte.

\section{CONSIDERAÇÕES FINAIS}

As análises realizadas por meio deste estudo permitem dizer que é necessário, no Ensino de Ciências, o desenvolvimento de abordagens pedagógicas que discutamos ciclo de vida e a morte. Assim, em termos de ciclo de vida, a importância se vê ratificada devido à especificidade/singularidade da constituição dele em cada indivíduo e, em termos de morte, pela sua oposição à vida, condição básica de todo ser vivo e objeto central de estudo da Biologia/Ciências.

A constatação acima precisa ser considerada, sob dois aspectos:

nos percentuais da $7^{\mathrm{a}}$ série $\mathrm{A}$, uma vez que a oscilação dos dados do pré ao pós-teste, especialmente quando determinam aumento da categoria alternativa e, consequentemente, diminuição da categoria clássica, pode ser resultado da abordagem pedagógica do ciclo de vida, desenvolvida durante as aulas e;

(b) na pouca alteração dos dados entre os estudantes da $7^{\mathrm{a}}$ série $\mathrm{B}$.

Chamamos a atenção para o fato de que se tem, a exemplo do observado na $7^{\mathrm{a}}$ série $\mathrm{B}$, comumente nas salas de Ciências, como proposta de ensino para o ciclo de vida e a morte, uma abordagem pedagógica que se limita à mera apresentação de informações triviais ${ }^{10}$ aos estudantes. Ou seja, com muita frequência são desconsideradas as curiosidades e são limitadas as discussões e interações que poderiam contemplar os diferentes pontos de vista que circulam em sala de aula.

Vale dizer ainda que a abordagem pedagógica, desenvolvida na $7^{\mathrm{a}}$ série $\mathrm{B}$, por atribuir ênfase excessiva ao discurso da ciência e por não considerar as especificidades da linguagem cotidiana, as interações entre os estudantes e a diversidade de ideias que emergem nas salas de aula dificultou a evolução conceitual, tanto em termos da conceituação do ciclo de vida como em termos de evolução das zonas do perfil conceitual de morte.

Ponto determinante para se reverter esse cenário parece ser o desenvolvimento de um processo de ensinar e de aprender, em termos de abordagem pedagógica, no Ensino de Ciências, que considere a tríade da condição humana, do encontro com o outro e do respeito à diversidade.

Por outro lado,um indício do sucesso da atividade ${ }^{11}$ desenvolvida, na $7^{\mathrm{a}}$ série A,em que os estudantes foram chamados a construir e a apresentar, por meio da organização de painéis com figuras, "outras possibilidades de constituição do ciclo de vida", foi a mudança presente nas respostas atribuídas para a conceituação do ciclo de vida, se comparadas aos

\footnotetext{
${ }^{10} \mathrm{Como}$, por exemplo, todo ser vivo tem ciclo de vida, ou seja, nasce, cresce, se reproduz, envelhece e morre.

${ }^{11}$ Fazemos menção ao sucesso da atividade esclarecendo que, a nosso ver, ele não foi garantido pela atividade em si, mas pela possibilidade, intrínseca a ela, de atender à tríade que já apresentamos nesse texto.
} 
dados do pré com os dados do pós-teste, apresentados no gráfico 01, no qual, como já dito anteriormente, a categoria clássica apresentou queda de $87,5 \%$, no pré-teste, para $66,7 \%$, no pós-teste, e a categoria alternativa aumento de $4,2 \%$, do pré-teste, para 33,3\%, no pós-teste. São exemplos de respostas que provocaram a oscilação nos dados: Pré-teste: "Nascer, crescer, se reproduzir, envelhecer e morrer" e Pós-teste: "Etapas que formam a vida de um ser. Nem todos vivem o Ciclo completo" ${ }^{12}$.

Da mesma forma, são respostas que ratificam a evolução e, consequentemente, a mudança de zona do perfil conceitual de morte, evidenciada pelos dados apresentados no gráfico 03, as atribuídas à questão sobre o que é morte: Pré-teste: "Morte é para mim algo que acontece com quem vive muito e fica velho. $E$ a passagem para outra vida" e Pós-teste " $E$ uma fase da vida. O fim da vida" ${ }^{\text {. }}$.

Assim sendo, podemos dizer que a atividade caracterizou-se como um exemplo de atividade que considera a tríade já apresentada neste estudo, em termos pedagógicos, posto que:

(a) Viabilizou, primeiramente, o reconhecimento da condição humana, já que cada estudante pôde expressar a sua individualidade, ou seja, as experiências vividas, expectativas, curiosidades, dúvidas, os receios e/ou as apreensões em relação à temática em discussão.

(b) Fez emergir as falas dos diferentes estudantes que compunham o grupo e o reconhecimento de que a aprendizagem ocorre na constante interação com os enunciados do outro, o que se dá por meio do encontro com o outro.

(c) Possibilitou o respeito à diversidade, uma vez que, primeiramente, os estudantes entraram em contato com a concepção de ciclo de vida trazida pelo discurso da ciência e, consequentemente, pelos materiais didáticos, que circulam nos espaços escolares. E, depois, puderam vivenciar a experiência de expor e confrontar suas ideias, no e com o grupo, para então propor outras possibilidades de constituição do ciclo de vida e refletir sobre suas percepções de morte. Ou seja, puderam por meio da atividade desenvolvida, durante a abordagem pedagógica da unidade ciclo de vida, refletir, ampliar e/ou alterar seus modos de falar e suas formas de pensar o ciclo de vida e a morte.

Em síntese, indicamos que a consideração das três orientações, apresentadas nesse texto, é o que se faz mais próximo daquilo que parece ser o ideal em termos de planejamento e abordagem pedagógica, no Ensino de Ciências. Primeiramente, por se tratar de uma abordagem pedagógica pautada na consideração daquilo que os estudantes sabem e na aproximação do conhecimento científico com o conhecimento cultural. Ou seja, no desenvolvimento de uma abordagem que considerará as dimensões históricas, culturais, filosóficas e socioculturais da ciência (EL-HANI; MORTIMER, 2007).

Em segundo, porque promoveu o confronto de diferentes concepções que emergem em sala de aula o que, consequentemente, possibilitou o reconhecimento das limitações, contradições e/ou condições que permeiam tais concepções.

E, em terceiro, por instigar o compartilhamento de concepções e o contato com as conceituações dos outros, possibilitando aos estudantes a ampliação de seus conhecimentos e a tomada de consciência de qual o melhor contexto para a utilização de cada uma das conceituações. Temos assim o reconhecimento de que os diferentes significados que um conceito pode apresentar não são inferiores ou superiores ao científico, mas culturalmente

\footnotetext{
${ }^{12}$ Respostas encontradas nos questionários de pré e pós-teste, identificado como Q412, de uma aluna, componente do GRUPO 3, da $7^{\mathrm{a}}$ série A, do ensino fundamental.

${ }^{13}$ Respostas encontradas nos questionários de pré e pós-teste, identificado como Q418, de uma aluna, componente do GRUPO 1 , da $7^{\mathrm{a}}$ série A, do ensino fundamental.
} 
adequados para diferentes esferas da vida, nas quais ocorre a atuação e a fala humana (ELHANI; MORTIMER, 2007).

\section{REFERÊNCIAS}

BAKHTIN, M.Estética da criação verbal. Tradução de Paulo Bezerra. Rio de Janeiro: Forense Universitária, 1981, 1986, 2003.

BAKHTIN, M.; VOLOCHINOV, V. N. Marxismo e filosofia da linguagem.Tradução de Michel Lahud e Yara Frateschi Vieira. 8. ed. São Paulo: Hucitec, 1997.

COUTINHO, F. A construção de um perfil conceitual para a vida.2005. 183f. Tese (Doutorado em Educação em Ciências) - Faculdade de Educação, Universidade Federal de Minas Gerais, Belo Horizonte, 2005.

EL-HANI, C. N.; MORTIMER, E. F. Multicultural education, pragmatism and the goals of science teaching. Cultural Studies of Science Education, v. 2, p. 657-687, 2007.

HOLQUIST, M. The dialogic imagination.Austin: University of Texas Press, 1981.

MINAYO, M. C. S. (Org). Pesquisa social:teoria, método e criatividade. 9.ed. São Paulo: Vozes, 1998.

MORTIMER, E. F.Construtivismo, mudança conceitual e o ensino de ciências: para onde vamos? In: investigações em ensino de ciências. 1:20-39, 1996.

.Perfil conceptual: formas de pensar y hablarenlasclases de ciencias. Infancia Y Aprendizaje, 24 (4): 475-490, 2001.

SILVA, F. O perfil conceitual para a vida:ampliando as ferramentas metodológicas para sua investigação. 2006. 160f. Dissertação(Mestrado em Educação em Ciências) - Faculdade de Educação, Universidade Federal de Minas Gerais, Belo Horizonte, 2006. 